\title{
Cotidiano e Territorialidade: Um Estudo de Usos do Tempo entre Assentado(a)s
}

\author{
Everyday and Territoriality: A Study of Time Use among Settled People
}

\author{
João Carlos Saldanha do Nascimento Santos \\ Universidade Federal do Espírito Santo \\ profsaldanha@hotmail.com
}

\begin{abstract}
Resumo
Trata-se de um estudo acerca das interações estabelecidas na organização da vida social de Projetos de Assentamentos Rurais, criados no Estado do Espírito Santo. A partir do estudo das atividades diárias das famílias assentadas, pretende-se descrever o processo de "regionalização" que estrutura a vida cotidiana, tendo como recorte as relações de gênero e de geração.
\end{abstract}

Palavras-chave: Gênero; Assentamentos Rurais; Territorialidade.

\begin{abstract}
This is a study of the interactions established in the organization of social life in Rural Settlement Projects created in Espírito Santo. From the study of daily activities of the settled families, it is intended to describe the process of "regionalization" that structure everyday life, focusing on the relationships between gender and generation.
\end{abstract}

Keywords: Gender; Rural Settlement; Territoriality. 


\section{Introdução}

No estudo da organização da vida cotidiana das famílias assentadas, a proposta é, a partir de uma perspectiva microssocial, identificar os aspectos presentes nas interações estabelecidas nos assentamentos rurais. São considerados aqueles aspectos que Simmel define como: "os delicados fios de relações mínimas entre os homens, em cuja repetição contínua se funda aquelas grandes formações" e, presentes também, nas "formas sociais poucos visíveis" em "status nascens"1, como no caso dos assentamentos rurais. E que, na perspectiva de análise adotada, podem ser identificados na 'territorialidade' das práticas sociais que se configuram nas dimensões tempo e espaço da vida cotidiana.

$\mathrm{Na}$ definição 'territorialidade', destacamos as noções elaboradas por Yves Barel, no artigo 'Le social $e$ ses territoires' que, segundo o autor, designa os limites e fronteiras de uma prática social. O 'território', ou como ele define, o 'território social' é parte constitutiva das dimensões espaço e tempo que é formado tanto de aspectos materiais, como dos imateriais. A definição de Barel trata as dimensões espaço e tempo no plano da concretude, como receptáculos que podem ser percebidos e (re) sentidos pelo homem. Nesta definição, aponta para a inevitabilidade dos indivíduos ou grupos humanos de produzir ou de habitar em mais de um 'território'. E com a noção de 'multiterritorialidade' explica o fato do indivíduo, viver, simultaneamente, no nível da família, do grupo e da nação. Barel observa, no entanto, que a 'multiterritorialidade' acarreta no fenômeno da 'superposição territorial', que traz à tona, por sua vez, o papel do paradoxo na vida humana e social com suas contradições e conflitos.

No enfoque proposto, parte-se da premissa que o cotidiano representa um 'lugar' privilegiado para a reconstrução das novas sociabilidades. Neste sentido, estamos em acordo com Milton Santos quando considera a necessidade de redescobrir o 'lugar', por meio do cotidiano, sobretudo, num contexto em que 'globalidade' e 'localidade' se chocam e se fundem. Nos assentamentos, mesmo distante dos centros de modernidade, os indivíduos estão em contato com os meios técnicos, científicos e informacionais, disponibilizados pela sociedade contemporânea e que estão presentes como recursos em suas atividades diárias como as motocicletas, as antenas parabólicas, celulares, microcomputadores, etc.

Porém, a condição fundamental para existência do grupo é a 'proximidade' por meio da qual se estabelecem os vínculos sociais. A partir desta perspectiva, procura-se explicitar a territorialidade das práticas sociais, analisando a natureza das interações sociais, os locais onde ocorrem e os atores sociais envolvidos. Observando que as interações cotidianas são 'regionalizadas', como na perspectiva assinalada por Goffman e Giddens, nos assentamentos são 'regionalizadas' em torno de práticas que se estabelecem em função das relações de parentesco, gênero, geração e vínculos políticos ou religiosos.

A pesquisa foi realizada em dois assentamentos rurais no norte do Estado do Espírito Santo: Pontal do Jundiá e Zumbi do Palmares. Estes assentamentos foram escolhidos em razão de dois critérios: por estarem localizados na região norte, onde se concentra o maior número de assentamentos no Estado, próximos dos municípios de São Mateus, Conceição da Barra e Nova Venécia; E por terem sido criados em diferentes épocas, visto que a intenção era pesquisar áreas em fases distintas da formação como o Pontal do Jundiá, surgida em meados da década de 1980 e o Zumbi dos Palmares no final da década de 1990.

O trabalho de campo aconteceu no correr de dois meses, quando visitei as áreas fazendo observações in loco e aplicando questionários, entrevistas e diários de usos do tempo. Para coletar os dados frequentei os assentamentos durante os meses de junho e julho de 2008, período final da colheita do café e de comemoração das festas juninas. O primeiro ocorreu nos dias 11,12 e 13 de junho, o segundo, nos dias 16 , 17,18 e 19 de junho e, o terceiro, nos dias 07, 08, 09, 10 e 11 de julho. Durante as visitas, apliquei os instrumentos de pesquisas e os intervalos de tempo foram necessários para contatar as famílias e realizar os procedimentos de campo.

Mapa 1: Assentamentos Rurais no ES

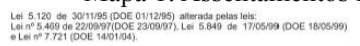

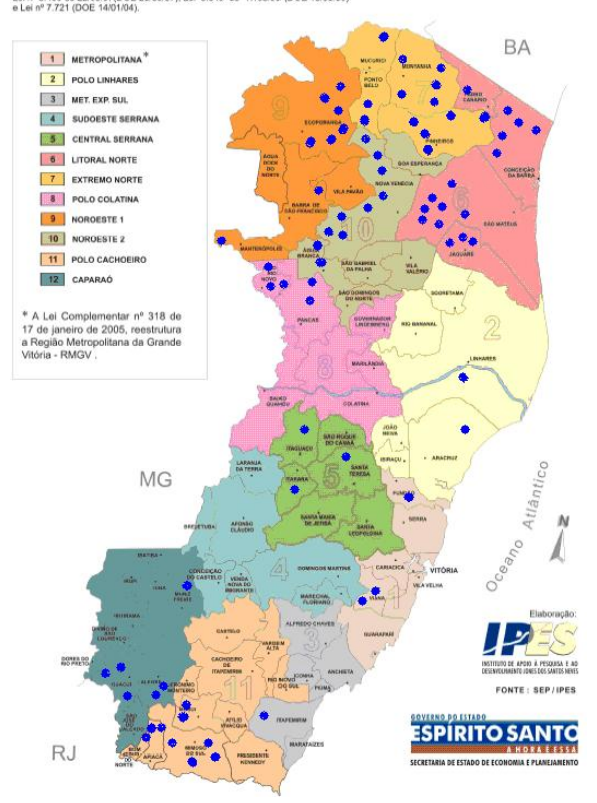


Mapa 2: Assentamentos Rurais pesquisados

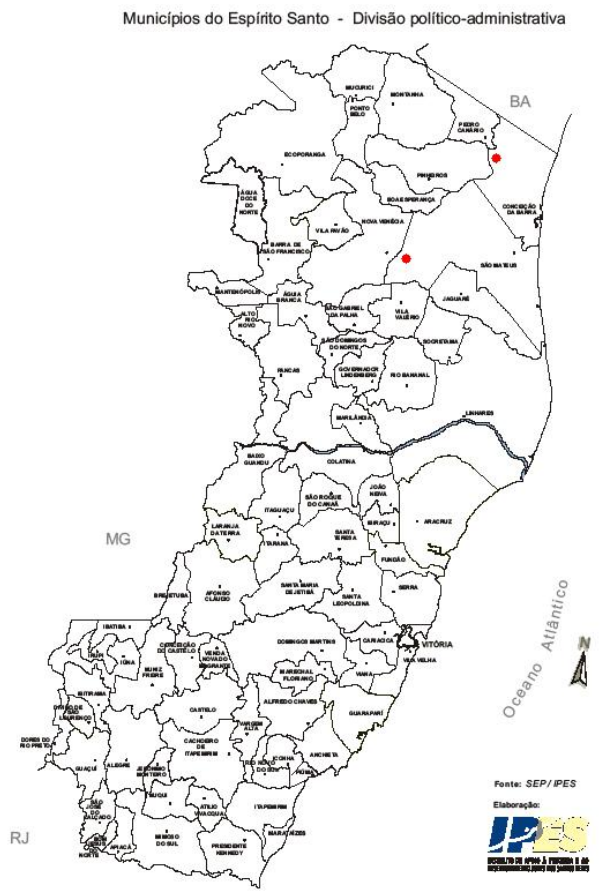

\section{Os Diários de Usos do Tempo no Estudo das Famílias Assentadas}

As possibilidades apresentadas pelo uso desta metodologia, foram as de alcançar uma amostra significativa de famílias e, pelo fato de ser autoaplicáveis, registrar as informações com expressões próprias dos sujeitos pesquisados. $\mathrm{Na}$ pesquisa de campo, os diários foram aplicados para colher informações do cotidiano dos assentados e a orientação era de que escolhessem um dia comum, do meio de semana para preenchê-lo. Os limites residiam na restrição da coleta de dados ao período de um dia e na necessidade de confiar em registros feitos sem a comprovação direta do pesquisador. $\mathrm{Na}$ superação dos limites, o procedimento adotado consistiu na combinação de com a observação direta, o questionário e a entrevista.

$\mathrm{Na}$ temporalidade da vida cotidiana dos assentados, chama-se a atenção para a distinção feita por E. P. Thompson a respeito das diferentes formas de percepção do tempo. No texto intitulado: 'Tempo, disciplina de trabalho e o capitalismo industrial', Thompson distingue as formas de percepção "orientadas pelas tarefas" das que são 'orientadas pelo relógio'. As 'orientadas pelas tarefas' são típicas das sociedades camponesas, dos vilarejos e da vida doméstica e as 'orientadas pelo relógio' típicas das sociedades industrializadas. Por viverem no mundo rural, as famílias assentadas são reguladas pelos dois ritmos. O ritmo da natureza que determina os momentos do plantio, da colheita, da irrigação e do trato, como o dia e a noite, as estações do ano e a posição do sol no decorrer do dia. Os ritmos do relógio e do calendário que determinam os momentos de cuidar da casa, ir para o trabalho, ir para escola, pegar ônibus, assistir televisão, ir às reuniões e cultos religiosos, pagar as contas, etc.

Ou seja, na organização dos seus espaços de vida, as famílias são sujeitas às temporalidades advindas de diferentes esferas: a da vida doméstica, que regula o tempo do sono, da alimentação, dos cuidados com a casa e com a família; a da produção que determina o tempo do plantio, do trato, da colheita e da venda; a da vida social com o horário da escola, das reuniões e das celebrações; e a do poder público, que ultrapassa os âmbitos das relações face à face, decorrente da temporalidade de tramitação dos projetos, convênios e financiamentos. Submetidos por esta múltipla temporalidade, os assentados configuram a territorialidade das suas vidas cotidianas, percorrendo pelos diferentes lugares como a casa, a área de produção, a comunidade, a escola, a igreja e a cidade próxima.

A partir dos registros feitos nos diários, se verificou as diferentes distribuições de usos dos tempos pelos indivíduos realizando as atividades, relacionando com pessoas e percorrendo pelos lugares. A dimensão quantitativa da pesquisa não tinha como intenção medir a duração dos eventos e sim verificar a proporção em que ocorrem. As proporções de distribuição dos tempos foram calculadas a partir da média dos tempos registrados e agrupados, em relação à categoria vínculo familiar. A amostra alcançou quarenta e nove indivíduos (Quadro 1) em vinte e nove famílias, distribuídas proporcionalmente nos dois assentamentos (Quadro 2).

\begin{tabular}{|c|c|c|c|}
\hline Quadro 1 & tra dos Diár & de Usos do Tempo & \\
\hline Vínculo familiar & $\begin{array}{c}\text { Zumbi dos } \\
\text { Palmares }\end{array}$ & Pontal do Jundiá & Total \\
\hline Esposa & 12 & 6 & 18 \\
\hline Esposo & 13 & 6 & 19 \\
\hline Filhas/filhos & 7 & 3 & 10 \\
\hline Genro/nora & 1 & 1 & 2 \\
\hline Total & 33 & 16 & 49 \\
\hline
\end{tabular}


Quadro 2

\begin{tabular}{cccc}
\hline Assentamento & Município & Famílias & Data de criação \\
PA Pontal da Jundiá & C. da Barra & 48 & $16 / 2 / 1986$ \\
\hline & & & \\
\hline PA Zumbi dos Palmares & São Mateus & 151 & $13 / 12 / 1999$ \\
\hline
\end{tabular}

Considerando o universo de cento e noventa e nove famílias cadastradas nos dois assentamentos, a amostra alcançou um percentual de quatorze por cento das famílias, com o "erro amostral tolerável" entre quinze e vinte por cento. De acordo com os resultados obtidos, foram verificados os aspectos descritos a seguir.

\section{Atividades}

$\mathrm{Na}$ escala de distribuição dos usos do tempo, as atividades com 'cuidados pessoais' apareceram em maior proporção. A esse respeito, é necessário observar que, nesta categoria, consta o 'dormir', que ocupa parte substancial jornada diária; sobretudo no meio rural, onde o tempo dedicado ao sono é, em geral, superior ao do meio urbano. Na segunda posição da escala, entre os esposos, o somatório dos tempos resultou nas atividades com o 'trabalho agrícola dentro do contexto doméstico' e, entre as esposas; no Zumbi dos Palmares, resultou no 'manejo com alimentos' e, no Pontal do Jundiá, no 'trabalho agrícola dentro do contexto doméstico'. Ou seja, o aspecto comum aos dois assentamentos é a divisão por gênero das atividades. As que dizem respeito aos cuidados com a casa aparecem como de responsabilidade das esposas e o trabalho agrícola dos esposos. No entanto, observa-se que as esposas também realizam o trabalho agrícola, enquanto que os esposos pouco participam das atividades domésticas.

O trabalho agrícola é realizado na área de produção que, em poucas situações, fica próximo da casa. Em geral, a casa e a área de produção são distantes. Com isto, os assentados gastam parte do tempo diário em deslocamentos realizados a pé, de moto ou de bicicleta. Nestes deslocamentos, percorrem pelas estradas e trocam informações com os demais membros da comunidade. Entremeiam o dia de trabalho com intervalos para descanso e tomar café, numa rotina que retrata um dos aspectos ressaltados nas conversas com os assentados que se refere à maior autonomia nas relações de trabalho conquistadas a partir do ingresso nos assentamentos.
As 'atividades participativas' como reuniões e assembleias apareceram com maior frequência entre os esposos. Outro aspecto comum presente, nos dois assentamentos, foi o registro de tempos dedicados aos trabalhos não agrícolas realizados dentro e fora dos lotes. Os dados expressam a 'pluriatividade' existente nos assentamentos em que, para garantir a reprodução econômica das unidades domésticas, os membros das famílias realizam atividades não agrícolas. Esta situação se verificou com maior frequência no Zumbi dos Palmares, onde se constatou uma média de idade inferior, em cerca de dez anos à do Pontal do Jundiá e, portanto, com maiores possibilidades de inserção nas atividades não agrícolas oferecidas como as de professor, agentes de saúde, domésticas, etc. Neste caso, a 'pluriatividade' envolve particularmente as esposas e filhos, pois, os esposos, mesmo quando buscam rendimentos fora dos lotes, realizam atividades agrícolas.

$\mathrm{Na}$ descrição das atividades, ressalta-se, o tempo dedicado a assistir televisão. Em relação aos meios de comunicação, a televisão apareceu numa proporção significativamente superior ao hábito de ouvir rádio. Nos registros dos diários, verifica-se que à noite as famílias se reúnem em frente à TV para acompanhar os jornais e novelas. Percorrendo pelos assentamentos percebe-se que a maioria das casas possui antenas parabólicas, por meio das quais estão conectadas com as informações circulantes nas mídias televisivas. Com isto, a televisão constitui num importante canal, por meio do qual recebem influências de agentes, situados distante do contexto direto das interações cotidianas.

Os filhos, por sua vez, dedicam parte do tempo diário ao 'trabalho agrícola' e 'não agrícola' e, com isto, desempenham papel importante na composição da renda familiar. Participam também das atividades escolares, visto que os dados demonstram que a escola faz parte do cotidiano das crianças e jovens, aparecendo com frequência nos registros dos diários. Os que cursam o ensino fundamental, estudam nas escolas localizadas nos assentamentos e os que cursam o ensino médio, se deslocam para as cidades próximas. No Pontal do Jundiá, se deslocam para Pedro Canário e no Zumbi dos Palmares, para Nova Venécia. No registro dos filhos e filhas e dos genros e noras, observou-se que estes, em razão das relações de gênero, participam do 'trabalho agrícola dentro do contexto doméstico' ou das atividades ligadas à manutenção do domicílio.

\section{Com Quem}

De acordo com os dados dos diários, as atividades cotidianas dos esposos e esposas são realizadas, na 
maior parte do tempo, sozinhas ou na companhia dos familiares e, no restante do tempo, com os 'demais membros da comunidade' ou 'outras pessoas conhecidas'. Pelo fato de cuidar das atividades da casa, a esposa tem um maior tempo junto com os filhos. Por outro lado, esposos por circularem com mais frequência fora de casa, estabelecem um maior contato com pessoas de fora do âmbito familiar. No entanto, nas visitas de campo presenciei situações de convívio social com o envolvimento de ambos, como nas reuniões em que discutiam questões referentes à renegociação dos créditos agrícolas e na preparação da festa junina.

Os filhos maiores, por estudarem na cidade ou exercerem 'trabalho não agrícola, fora do contexto doméstico', se relacionam numa proporção maior de tempo que os pais, com os demais 'membros da comunidade' ou 'outras pessoas conhecidas'. Nestas relações, ampliam as redes de conhecimentos e as relações para além do âmbito familiar. A múltipla convivência possibilita aos mais jovens o ingresso em atividades não agrícolas realizadas dentro ou fora dos assentamentos. Como exemplo, os diversos casos de filhos de assentados que, depois de concluírem o segundo grau, se graduaram em cursos de pedagogia e técnicos agrícolas.

\section{Onde}

Sobre o 'onde fazem' as informações dos diários indicam que, as atividades cotidianas da família ocorrem no âmbito da casa e da área de produção e são 'regionalizadas' de acordo com as relações de gênero e de geração. A jornada da esposa acontece, prioritariamente, nos espaços da casa, cuidando do lar, das crianças, do alimento, da horta e da criação de quintal e, em menor proporção, na área de produção e na comunidade. A casa para os esposos é o lugar do descanso, o trabalho é realizado na área de produção, onde permanecem durante parte, considerável, do dia e o restante do tempo dividido entre a comunidade e a cidade próxima para onde se deslocam para pagar contas, fazer compras, ir ao banco, etc. Na tabela abaixo, relacionamos as expressões registradas por esposos e esposas na regionalização das atividades diárias.

Os registros foram relacionados em ordem de ocorrência, destacando os três primeiros lugares e utilizando as expressões próprias dos pesquisados. A área de moradia é referida como casa e a área de produção aparece com diferentes expressões. Em geral, se referem à área de produção como roça, porém, por vezes aparecem as expressões propriedade e lavoura. De cada expressão é possível apreender diferentes
Quadro 3 - Regionalização dos episódios (esposo e esposa)

\begin{tabular}{|c|c|c|c|c|c|c|c|}
\hline Vinculo & Lugar 1 & Lugar 2 & $\begin{array}{c}\text { Lugar } \\
3\end{array}$ & Vínculo & Lugar 1 & Lugar 2 & Lugar 31 \\
\hline Esposa & Casa & Roça & & Esposo & lavoura & casa & \\
\hline Esposa & Casa & Roça & s/info. & Esposo & roça & casa & s/info. \\
\hline Esposa & Casa & Roça & s/info. & Esposo & roça & casa & s/info. \\
\hline Esposa & Casa & s/info. & s/info. & Esposo & roça & casa & Cidade \\
\hline Esposa & Casa & s/info. & s/info. & Esposo & roça & casa & Escola \\
\hline Esposa & Casa & Rua & s/info. & Esposo & roça & casa & Cidade \\
\hline Esposa & Casa & s/info. & s/info. & Esposo & casa & roça & s/info. \\
\hline Esposa & Roça & Casa & s/info. & Esposo & casa & roça & s/info. \\
\hline Esposa & Casa & s/info. & s/info. & Esposo & propriedade & roça & s/info. \\
\hline Esposa & Casa & Roça & s/info. & Esposo & propriedade & casa & Igreja \\
\hline Esposa & Casa & Roça & s/info. & Esposo & roça & casa & s/info. \\
\hline Esposa & Escola & Casa & s/info. & Esposo & roça & casa & Vizinho \\
\hline Esposa & Casa & s/info. & s/info. & Esposo & casa & roça & Cidade \\
\hline Esposa & Casa & propriedade & Vizinha & Esposo & casa & propriedade & Grupo \\
\hline Esposa & Casa & s/info. & s/info. & Esposo & casa & roça & Vila \\
\hline Esposa & Casa & Escola & s/info. & Esposo & roça & casa & s/info. \\
\hline Esposa & Casa & Roça & s/info. & Esposo & casa & assentamento & Roça \\
\hline Esposa & Casa & Roça & Igreja & Esposo & roça & casa & s/info. \\
\hline Esposa & Casa & Roça & s/info. & Esposo & casa & roça & s/info. \\
\hline Esposa & Casa & s/info. & s/info. & Esposo & roça & casa & s/info. \\
\hline Esposa & Casa & s/info. & s/info. & s/info. & s/info. & s/info. & s/info. \\
\hline Esposa & Casa & s/info. & s/info. & s/info. & s/info. & s/info. & s/info. \\
\hline
\end{tabular}

sentidos, a roça como o lugar do trabalho, a propriedade da autonomia e a lavoura da produção. As expressões de 'vizinho' e 'grupo', se referem às imediações próximas do âmbito familiar e a "igreja" o local dos encontros religiosos.

Os filhos circulam entre a casa, a área de produção, a comunidade e a cidade. Na casa, as filhas participam das atividades domésticas, enquanto que nos lotes, os filhos, acompanham os pais no trabalho agrícola. As escolas de assentamentos constituem-se como um ponto de referência nas comunidades para onde se encaminham, a pé ou transporte escolar, as que estudam no primeiro segmento do ensino básico. Sendo que, aqueles prosseguem na escolarização se encaminham para a cidade próxima por meio dos 
transportes disponibilizados pelas prefeituras. Os que realizam atividades agrícolas na cidade, muitas vezes, retornam para casa somente nos finais de semanas. E as atividades registradas por genro/nora aconteceram, quase na totalidade, na casa. No quadro de 'regionalização' ${ }^{3}$ dos eventos, encontramos a seguinte configuração:

Quadro 4 - Regionalização dos Episódios Filho-Filha / Genro - Nora

\begin{tabular}{l|c|c|c|}
\hline Vínculo & Lugar 1 & Lugar 2 & Lugar 3 \\
Filha & Casa & Escola & \\
\hline Filha & Cidade & Casa & s/info. \\
\hline Filha & Casa & Escola & Cidade \\
\hline Filho & Roça & Casa & s/info. \\
\hline Filho & Casa & Escola & \\
Filho & Casa & s/info. & s/info. \\
Filho & Casa & s/info. & s/info. \\
\hline Filho & Escola & Casa & s/info. \\
Filho & Roça & Casa & Cidade \\
Nora & Casa & Roça & s/info. \\
Nora & Casa & s/info. & s/info. \\
\hline
\end{tabular}

\section{Conclusões}

As informações coletadas nos diários, permitiram constatar que a base da vida social no microcosmo, dos assentamentos pesquisados, são as unidades domésticas, sendo que as atividades cotidianas são executadas em razão das relações de gênero e geração. As unidades domésticas, são constituídas de diferentes maneiras, com indivíduos separados após o ingresso nos assentamentos, famílias nucleares formadas pelos casais e filhos e famílias extensas com membros de duas ou três gerações no mesmo lote. Este microcosmo é dividido por dois espaços fundamentais: a área e moradia e a área de produção. Em geral, para os maridos a área de moradia é o lugar do descanso e para as esposas o lugar de trabalho e de descanso. As exceções acontecem no caso dos indivíduos separados, que exercem tanto as atividades domésticas quanto as agrícolas. As esposas circulam menos que os maridos, no entanto se envolvem num número maior de episódios, no decorrer do dia: preparando a comida, cuidando dos filhos, arrumando a casa e tratando da horta e da criação do quintal, etc. Os maridos, por sua vez, circulam mais que as esposas, porém se envolvem num número menor de episódios e em atividades repetitivas no trabalho agrícola. Como conclusão, podemos observar nos assentamentos rurais uma dualidade que se traduz nos termos que, simultaneamente, se opõem e se complementam (Quadro 5).

Quadro 5
Feminino

Área de Moradia

Casa/Quintal

Atividades Domésticas

Fixidez
Masculino

Área de Produção

Roça

Atividades Agrícolas

Mobilidade
Simmel (1983, p. 71 e 73).

Thompson (1998).

Para Anthony Giddens os lugares ou, como ele prefere, os 'locais' são 'regionalizados' internamente e esta 'regionalização' é importante na constituição dos contextos de interação. Na 'teoria da estruturação' a noção de 'regionalização' corresponde ao zoneamento tempo espaço das práticas sociais rotinizadas, sendo que esta noção pode ser aplicada também em cenários de locais pequenos.

\section{Referências}

Aguiar, Neuma. Pesquisa dos Usos de Tempo / Belo Horizonte (Livro de Códigos). Belo Horizonte. 2002.

Barel, Yves. Le social et ses territoires. In: AURIAC Franck; BRUNET Roger Espaces, Jeux et Enjeux. Paris: F. D. Fayard. 1986.

Chayanov, Alexander. La familia campesina y la influencia de su desarrollo en actvidad económica. In: CHAYANOV, Alexander. La organización de la unidade económica campesina. Buenos Aires: Editorial Nueva Visión, 1974.

Giddens, Anthony. A Constituição da Sociedade. São Paulo: Livraria Martins Fontes, 1989. 
Cotidiano e Territorialidade: um Estudo de Usos do Tempo

entre Assentado(a)s

Goffman, Erving. A representação do eu na vida cotidiana. Petrópolis: Vozes. 2007.

Leite, Sérgio; HEREDIA, Beatriz; MEDEIROS; Leonilde (et al.). Impactos dos assentamentos. São Paulo: UNESP. 2004

PIZETTA, Adelar João. A questão agrária e o MST no Espírito Santo. São Mateus: MST, 1999.

Santos, Milton. A Natureza do Espaço. São Paulo: Editora da Universidade de São Paulo, 2006.

Thompson, Edward Palmer. Tempo. Costumes em comum. São Paulo: Companhia das Letras, 1998.

Recebido em 20 de agosto de 2010. Aceito em 08 de março de 2011.

J oão Carlos Saldanha do Nascimento Santos 